\title{
Editorial: Historical Reconstructions of Marine Fisheries Catches: Challenges and Opportunities
}

\author{
Daniel Pauly and Maria Lourdes D. Palomares* \\ Sea Around Us, Institute for the Oceans and Fisheries, University of British Columbia, Vancouver, BC, Canada
}

Keywords: Asia, Africa, Caribbean, Mediterranean, marine fisheries, catch time series

\section{Editorial on the Research Topic}

\section{Historical Reconstructions of Marine Fisheries Catches: Challenges and Opportunities}

Fishing is conducted to generate a catch, and hence the success or not of a fishery ought to be measured by its catch. Not over a short time: it is too easy to pillage a resource and generate high catches for a short time. The point is to generate reasonably high catches over a longer time period. Few fishing cultures appear to have been able to achieve this. Of the few examples, those that come to mind are: Polynesia with its century old coral-reef based fisheries, and the Pacific Northwest, where salmon-based cultures, including individual villages, have persisted for millennia.

Thus, a long-term perspective is required to evaluate the status of fisheries. The challenge, however, for most fisheries, is that quantitative data from centuries past are difficult or impossible to obtain. Thus, for the catch reconstruction work undertaken by the Sea Around Us, 1950 was chosen as a compromise, to balance as early a date as possible, with data availability. The year 1950 was the first year of the decade that followed on the murderous 1940s, marred by a series of conflicts which culminated in the Second World War. Physical and administrative structures were being rebuilt and the United Nations and its "technical organizations" (including the Food and Agriculture Organization, i.e., FAO) started their project of quantifying the world (Ward, 2004), which-among other things-resulted in FAO issuing from 1950 an extremely useful Yearbook of Fisheries Statistics (now replaced by a website from which its world fisheries and aquaculture statistics are made available). Thus, 1950 was an appropriate year to choose as a baseline for a reconstruction of catches of the world's marine fisheries.

Also, because the re-industrialization of the fisheries in richer countries had just begun, for example, in Russia (Popov and Zeller) or Bulgaria (Keskin et al.) and of what was later to become developing countries of Africa, the Caribbean, and Asia, were still colonies of European countriesfor example, Vanuatu (Léopold et al.) and the Pitcairn Islands (Coghlan et al.). Also, the catches from the early 1950s offered a stark contrast to the later growth of fisheries in the global south, as in Thailand (Derrick et al.), the Turk and Caicos Islands (Ulman et al), or Oman (Khalfallah et al.). This provides the context for the seven contributions in this research topic based on Sea Around Us catch reconstructions.

Of the other six contributions, half reach even deeper back into the past, and thus provide deep insights on ecosystem changes in the Mediterranean (Fortibuoni et al.), the small-scale fisheries of Flores, Indonesia (Ramenzoni), and the oyster fishery of Chesapeake Bay, USA (Schulte). The three other contributions, with shorter time horizons, focus instead on important issues, ranging from the effectiveness of monitoring, control, and surveillance in West Africa, where much of the coastal catch is illegally taken by distant water fleets from Asia and Europe (Doumbouya et al.), and the local ecological knowledge (Macusi et al.) and the incomes of small-scale fishers in the Philippines (Anticamara and Go). 
To complete the history of each fishery, these contributions required the assembling of hard-to-obtain older time-series data and filling the gaps using qualitative inferences and reasonable assumptions. As such, these contributions jointly document the impact of the "shifting baseline" concept (Pauly, 1995), which highlighted the accommodation with the biodiversity loss that results from ignoring past evidence of species abundance. Indeed, the one-page contribution in which this argument was presented is nowadays seen as one of the founding documents of "marine historical ecology," a now vibrant (sub-) discipline of ecology (Engelhard et al., 2015).

Marine historical ecology generates, in rigorous fashion, insights about the past exploitation and states of marine ecosystems to inform current management. In the process, practitioners have been able to demonstrate that past population abundance that are projected backward from present abundances and trends often miss the mark, while abundances reconstructed using the various methods of marine historical ecology tend to be much higher than initially assumed, as stunningly illustrated by Rosenberg et al. (2005). This obviously is of utmost

\section{REFERENCES}

Engelhard, G. H., Thurstan, R. H., MacKenzie, B. R., Alleway, H. K., Bannister, R. C., Cardinale, M., et al. (2015). ICES meets marine historical ecology: placing the history of fish and fisheries in current policy context. ICES J. Mar. Sci. 73, 1386-1403. doi: 10.1093/icesjms/ fsv219

Pauly, D. (1995). Anecdotes and the shifting baseline syndrome of fisheries. Trends Ecol. Evol. 10: 430.

Rosenberg, A. A., Bolster, W. J., Alexander, K. E., Leavenworth, W. B., Cooper, A. B., and McKenzie, M. G. (2005). The history of ocean resources: modeling cod biomass using historical records. Front. Ecol. Environ. 3, 78-84. doi: 10.1890/ 1540-9295(2005)003[0078:THOORM]2.0.CO;2 importance for public policy, e.g., in debates about rebuilding fish populations that have been impacted by overfishing.

We thus hope that the contributions herein will not only assist in managing the fisheries in question, but will also, either as jointly or individually, encourage the further development of marine historical ecology, and thus help society make informed decisions while managing marine fisheries resources.

\section{AUTHOR CONTRIBUTIONS}

MP led the editing of the research topic with help and advice from DP.

\section{ACKNOWLEDGMENTS}

The Sea Around $U s$ is a research initiative at the University of British Columbia supported by the David and Lucile Packard Foundation, Marisla Foundation, MAVA Foundation, Oak Foundation, and Paul M. Angell Family Foundation.

Ward, N. (2004). Quantifying the World: UN Ideas and Statistics. Bloomington, IN: Indiana University Press, 329.

Conflict of Interest Statement: The authors declare that the research was conducted in the absence of any commercial or financial relationships that could be construed as a potential conflict of interest.

Copyright (C) 2019 Pauly and Palomares. This is an open-access article distributed under the terms of the Creative Commons Attribution License (CC BY). The use, distribution or reproduction in other forums is permitted, provided the original author(s) and the copyright owner(s) are credited and that the original publication in this journal is cited, in accordance with accepted academic practice. No use, distribution or reproduction is permitted which does not comply with these terms. 